\title{
Editorial
}

\section{Editorial: Do-Not-Resuscitate Orders and Advance Directives-Existential Issues for Orthopaedic Patients with Life-threatening Conditions}

\author{
Seth S. Leopold MD
}

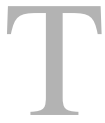
he vast majority of orthopaedic procedures are elective, and end-of-life care represents only a small part of most practices. Orthopaedic traumatologists and musculoskeletal tumor specialists deal with death more frequently than the rest of us, and I have to imagine that most of us are content not to face existential issues with our patients very often.

The author certifies that he, or any members of his immediate family, has no commercial associations (eg, consultancies, stock ownership, equity interest, patent/licensing arrangements, etc) that might pose a conflict of interest in connection with the submitted article.

All ICMJE Conflict of Interest Forms for authors and Clinical Orthopaedics and Related Research ${ }^{\circledR}$ editors and board members are on file with the publication and can be viewed on request.

The opinions expressed are those of the writers, and do not reflect the opinion or policy of $C O R R^{\mathbb{R}}$ or The Association of Bone and Joint Surgeons ${ }^{\mathbb{R}}$.

\section{S. S. Leopold MD ( $₫)$}

Clinical Orthopaedics and Related

Research $\mathbb{R}$, Philadelphia, PA 19103 ,

USA

e-mail: sleopold@clinorthop.org
But every orthopaedic surgeon who takes call will, as a matter of routine, treat one common life-threatening injury: Hip fracture. More than a quarter-million patients-mostly women-sustain hip fractures each year in the United States alone [10], and more women die from hip fractures than from breast and endometrial cancers combined [4, 14]. Men who experience hip fractures are even more likely to die within a year of the injury than are women [15]. Although hip fracture surgery alone accounts for half of the in-hospital deaths that occur after orthopaedic surgery [8], it is not the only "routine" diagnosis that should prompt a conversation about end-of-life issues. For example, the inhospital risk of death in a patient with septic arthritis from Staphylococcus aureus, a common-enough problem, is in the range of $5 \%$ to $13 \%[1,17]$ comparable to or greater than the risk of mortality following hip fracture surgery, which has been estimated at $2 \%$ to $5 \%[2,8,19]$.

Because of this, every time an orthopaedist admits a patient to the hospital with a potentially life-threatening surgical condition, (s)he should explore two topics: Code status (including the do-not-resuscitate, or DNR, order), and, more broadly, the wishes expressed in the patient's advance directive. In an article published this month in Clinical Orthopaedics and Related Research ${ }^{\circledR}$, Drs. Dunn, Ahn, and Bernstein from the University of Pennsylvania suggest that care teams seldom perform this sort of care planning with their hipfracture patients (DOI: 10.1007/ s11999-015-4675-1) [11]. This should be an easy problem to solve, and it is important that we solve it.

Unfortunately, how to handle endof-life planning in general, and DNR in particular, causes confusion and tension among surgeons, internists, and anesthesiologists. It causes confusion because the term "resuscitate" is vague and easily misconstrued. In the operating room, resuscitation entails much more than chest compressions, which rarely are needed during surgery. At issue are all of the other morecommon resuscitative interventions 
performed routinely during anesthesia in the older patient, including the use of vasopressors, anti-arrhythmic drugs, and endotracheal intubation. Dips in blood pressure, new-onset arrhythmias, and respiratory depression all occur frequently during (and in the days following) surgery, and often are iatrogenic. If the physicians who have induced these physiologic changes are prevented from reversing them, these providers quickly find themselves in an uncomfortable position. Indeed, because of this, some may opt not to provide surgical care to patients with DNR orders, perhaps denying those patients reasonable interventions. Or, as bad, providers may administer treatments during or after surgery that a patient would not have endorsed.

The topic causes tension because some patient-advocates believe that physicians who ask patients to rescind DNR orders in advance of surgery do so for self-interested reasons having to do with publicly tracked quality-ofcare metrics [7]. This is a common discussion topic on lay websites [3] and those sites' portrayals of physicians and their motives are not always flattering [12]. The Institute of Medicine's extensive report about care systems and insurance issues pertaining to patients in end-of-life situations was silent on the kinds of incentives that payors might exert in this setting, although certainly this seems worthy of attention [13]. Further complicating matters is that anesthesiologists do not concur about what exactly their obligations are. Viewpoints range from: "Most anesthesiologists find it untenable to be required to provide anesthesia to a patient yet be prohibited from resuscitating the patient from complications accompanying the delivery of anesthesia" [16] to "patients do not check their rights to selfdetermination at the OR doors ... policies automatically suspending or upholding DNR orders in the OR [are] ethically suspect, and ... rediscussion of the DNR order should occur, whenever possible, prior to undertaking surgery and anesthesia" [18].

Perhaps because of these disagreements, practice patterns vary widely, and large proportions of practitioners (18\% of anesthesiologists, $34 \%$ of internists, and $38 \%$ of surgeons in one study) believe that DNR orders should automatically be suspended during surgery [9]. Neither the American College of Surgeons [5] nor the American Society of Anesthesiologists [6] endorse that belief. Both suggest that a detailed conversation take place between the care team and the patient or the patient's designee to define what sorts of resuscitative efforts the patient is willing to undergo during and after surgery.

While the DNR order during surgery is perhaps the most acute concern, numerous issues pertaining to end-oflife care should be discussed whenever one admits a patient with a potentially life-threatening condition to the hospital. Although patients or their designees often complete advance-directive paperwork upon hospital admission, the stress of the moment and the large volume of other papers that get signed as part of that process may result in patients not reading these documents carefully. Surgeons need to foster explicit, detailed, and informed conversations on this topic with patients and families. Absent these conversations, there is no certainty that the signed documents reflect the patient's actual wishes, and the care team may not know what those wishes are. Any number of nuances and complexities can arise during a hospital stay, even when the operation itself goes smoothly. Dr. Bernstein's paper in this month's $C O R R^{\circledR} \quad$ (DOI: 10.1007/s11999-015-4675-1) [11] suggests that we may not be addressing these complexities attentively enough.

It should not be difficult to do better. One can imagine creating a checklist to consult when a patient with a life-threatening condition, including straightforward hip fractures, is admitted to the hospital. Such a checklist might include:

- Identifying the individual who will help make medical decisions on the 


\section{Editorial}

patient's behalf should the patient lose the capacity to do so;

- Determining whether end-of-life planning has been done, verifying that the patient's documents and previously expressed wishes about the topic reflect the patient's current desires in light of the new diagnosis (these desires may change in the face of existential threat), becoming familiar with these wishes, and sharing the substance of this discussion with all members of the care team, and, perhaps most importantly;

- Discussing exactly what "DNR" means in the context of the planned procedure(s); in many situations, the "DNR" order indeed should be modified or suspended for a period of time during and after surgery, but this should be done only in consultation with the patient or the patient's designee.

How do you manage these challenges in your practice? Share your approaches with CORR's readers in a letter to the editor, at EIC@ clinorthop.org.

\section{References}

1. Al-Nammari SS, Bobak P, Venkatesh R. Methicillin resistant staphylococcus aureus versus methicillin sensitive staphylococcus aureus adult haematogenous septic arthritis. Arch Orthop Traum Surg. 2007; 127:537-542.

2. Alzahrani K, Gandhi R, Davis A. Mahomed, N. In-hospital mortality following hip fracture care in southern Ontario. Can J Surg. 2010;53:294-298.

3. AlzConnected Discusion Board. DNR not in force during surgery. Available at https://www.alzconnected.org/archive.aspx $? \mathrm{~g}=$ posts $\& \mathrm{t}=$ 5742. Accessed on December 14, 2015.

4. American Cancer Society. Cancer facts and figures 2013. Available at http://www.cancer.org/acs/groups/ content/@epidemiologysurveilance/documents/document/acspc-036845.pdf. Accessed on December 14, 2015.

5. American College of Surgeons. Statement on advance directives by patients: "Do not resuscitate" in the operating room. Bull Am Coll Surg. 2014;99:42-43.

6. American Society of Anesthesiologists. Ethical guidelines for the anesthesia care of patients with donot-resuscitate orders or other directives that limit treatment. Approved by the ASA House of Delegates on October 17, 2001, and last amended on October 16, 2013. Available at: http://www.asahq.org/ /media/Sites/ ASAHQ/Files/Public/Resources/standards-guidelines/ethical-guidelinesfor-the-anesthesia-care-of-patients.pdf. Accessed on December 14, 2015.

7. Berman A. Can someone override your advance directive? Available at http://www.jhartfound.org/blog/cansomeone-override-your-advance- directive/. Accessed on December 14, 2015.

8. Bhattacharyya T, Iorio R, Healy WL. Rate of and risk factors for acute inpatient mortality after orthopaedic surgery. $J$ Bone Joint Surg Am. 2002;84-A:562-572.

9. Burkle CM, Swetz KM, Armstrong MH, Keegan MT. Patient and doctor attitudes and beliefs concerning perioperative do not resuscitate orders: Anesthesiologists' growing compliance with patient autonomy and self-determination guidelines. BMC Anesthesiology. 2013;13:2.

10. Centers for Disease Control and Prevention. Hip fractures in older adults. Available at http:// www.cdc.gov/homeandrecreationalsafety/falls/adulthipfx.html. Accessed on December 17, 2015.

11. Dunn RH, Ahn J, Bernstein J. Endof-life Care Planning and fragility fractures of the hip: Are we missing a valuable opportunity? [Published online ahead of print December 21, 2015]. Clin Orthop Relat Res. DOI: 10.1007/s11999-015-4675-1.

12. GlockTalk.com. Do doctors have to follow living wills \& DNR's? Available at http://www.glocktalk.com/threads/do-doctors-have-to-follow-living-wills-dnrs. 1574674/. Accessed on December 14, 2015.

13. Institute of Medicine of the National Academies, Committee on Approaching Death. Dying in America: Improving quality and honoring individual preferences near the end of life - Key findings and recommendations. 2014. Available at: https:// iom.nationalacademies.org/ /media/ 
Files/Report\%20Files/2014/EOL/Key\% 20Findings \% 20and\%20Recommen dations.pdf. Accessed December 28, 2015.

14. International Osteoporosis Foundation. Facts and statistics. Available at http:// www.iofbonehealth.org/facts-statis tics. Accessed on December 14, 2015.

15. Kannegaard PN, van der Mark S, Elken P, Abrahamsen B. Excess mortality in men compared with women following a hip fracture National analysis of comedications, comorbidity and survival. Age Ageing. 2010;39:203-209.
16. Kelly RJ. Perioperative do-not-resuscitate orders. Available at http:// www.asahq.org/resources/publications/ newsletter-articles $/ 2014 / \mathrm{march}$ 2014/perioperative-do-not-resuscitate-orders. Accessed on December 14, 2015.

17. Lin WT, Wu CD, Cheng SC, Chiu CC, Tseng CC, Chan HT, Chen PY, Chao CM. High prevalence of methicillin-resistant staphylococcus aureus among patients with septic arthritis caused by staphylococcus aureus. PLoS One. 2015;10:e0127 150.
18. Van Norman G. Do-not-resuscitate orders during anesthesia and urgent procedures. Available at https:// depts.washington.edu/bioethx/topics/dnrau.html, last modified October 22, 2010. Accessed on December 14, 2015.

19. Le Manach Y, Collins G, Bhandari M, Bessissow A, Boddaert J, Khiami F, Chaudhry H, De Beer J, Riou B, Landais $\mathrm{P}$, Winemaker $\mathrm{M}$, Boudemaghe T, Devereaux PJ. Outcomes after hip fracture surgery compared with elective total hip replacement. JAMA. 2015;314:1159. 